\title{
Control Striving in Older Adults With Serious Health Problems: A 9-Year Longitudinal Study of Survival, Health, and Well-Being
}

\author{
Nathan C. Hall \\ University of Maryland, College Park \\ Jutta Heckhausen \\ University of California, Irvine
}

\author{
Judith G. Chipperfield \\ University of Manitoba
}

Raymond P. Perry

University of Manitoba

\begin{abstract}
The present longitudinal study of 143 older adults (73-98 years) with serious health problems (arthritis, heart disease, heart attack, stroke) examined the effects of goal engagement, disengagement, and self-protection control strategies on self-rated physical health (condition severity, functional status) and subjective well-being (life satisfaction) at 5 years and survival at 9 years. Main effects and interactions between strategy use and the occurrence of an acute vascular event (no, yes) as well as age (young-old vs. old-old) were assessed. As hypothesized, goal engagement predicted greater survival for individuals with acute conditions but poorer physical health for those with chronic conditions and among old-old adults. In contrast, goal disengagement predicted poorer physical health for those with acute conditions but better health for individuals with chronic conditions and old-old adults. Self-protective strategies (positive reappraisal) predicted greater survival, health, and subjective well-being for those with acute conditions, as well as better physical health for old-old adults.
\end{abstract}

Keywords: control striving, goal engagement, older adults, serious health problems

As individuals age, they are increasingly faced with challenges that threaten their capacity for control over their daily lives. Empirical research suggests that the adaptive use of control strategies involving goal engagement (e.g., persistence), disengagement (e.g., downgrading expectations), and self-protection (e.g., positive reappraisal) can promote health, adjustment, and survival among older adults with serious health problems (Chipperfield \& Perry, 2006; Chipperfield, Perry, Bailis, Ruthig, \& Chuchmach, 2007; Wahl, Becker, Burmedi, \& Schilling, 2004; Wrosch, Heckhausen, \& Lachman, 2000). Based on the life-span theory of control (Heckhausen, Wrosch, \& Schulz, 2010; see also Heckhausen \& Schulz, 1995; Schulz \& Heckhausen, 1996), findings suggest that the benefits of control strategies are moderated by the

Nathan C. Hall, Department of Human Development, University of Maryland, College Park; Judith G. Chipperfield and Raymond P. Perry, Department of Psychology, University of Manitoba, Winnipeg, Canada; Jutta Heckhausen, Department of Psychology and Social Behavior, University of California, Irvine.

This study was supported by a postdoctoral fellowship to Nathan C. Hall and operating grants to Raymond P. Perry (510-2002-0059, 410-20072225) from the Social Sciences and Humanities Research Council of Canada, and Canadian Institutes of Health Research Operating Grant SSC-42790 to Judith G. Chipperfield. The cooperation of the Laboratory for Aging and Health Research at the University of Manitoba and the Laboratory on Life-Span Development and Motivation at the University of California, Irvine, was essential to the success of this project.

Correspondence concerning this article should be addressed to Nathan C. Hall, Department of Human Development, University of Maryland, 3304P Benjamin Building, College Park, MD 20742-1821. E-mail: halln@ umd.edu opportunities for control afforded by one's health condition (e.g. benign symptoms vs. degenerative illness; Wrosch, Schulz, \& Heckhausen, 2002) and one's capacity for control as a function of age (Chipperfield, Perry, \& Menec, 1999). Whereas goal engagement should be most effective for older adults with potentially reversible health problems or greater physical resources (youngold adults), disengagement or self-protection should be more beneficial for older adults with debilitating chronic conditions or limited capacities (old-old adults). Following this research, the present study explored the long-term effects of control striving for older adults with serious health conditions on physical health, psychological well-being, and survival, with a specific focus on how these effects are moderated by both opportunities for control (i.e., acute health events) and one's capacity for control as a function of age.

\section{The Life-Span Theory of Control}

In their examination of goal engagement from a life-span perspective, Heckhausen and colleagues (Heckhausen, 2000; Heckhausen \& Schulz, 1995; Heckhausen et al., 2010; Schulz \& Heckhausen, 1996) proposed a dual-process, motivational theory of life-span development-referred to as the life-span theory of control-that captures how people adapt their behavior to age-related changes in opportunities for control striving. According to this theory, people are universally motivated to directly engage their environment and exert control over developmental challenges across the life span (i.e., "primary control"), and are threatened by events that compromise opportunities for control. Further, this developmental theory proposed that the life-span capacity for primary control is optimized by engagement strategies aimed at 
proactively changing the environment (e.g., persistence, goal commitment) when control opportunities are present, and by disengagement and self-protection strategies (classified as "compensatory secondary control") when control opportunities are limited. The capacity for future control striving is an integral component of this theory, such that self-protection and disengaging from a goal are beneficial insofar as they prevent the futile investment of motivational resources and redirect them toward productive endeavors (Heckhausen \& Schulz, 1995, 1999).

The life-span theory is well suited to exploring how older adults adjust to health problems in providing a four-part classification of control strategies used to deal with age-graded changes in opportunities for control (see Heckhausen, 1997; cf. Baltes \& Baltes, 1990). Of the three control strategies aimed at goal engagement, the first, selective primary control, is most direct and involves the sustained or increased investment of personal resources such as time, effort, and skills to achieve one's goals. The second engagement strategy, compensatory primary control, is more indirect and entails the recruitment of external resources when one's own capabilities are not sufficient, such as the assistance of others or use of technical aids. The third engagement strategy, selective secondary control, is focused on increasing volitional commitment to a chosen goal, for example, by enhancing the perceived value of a given goal (e.g., Gollwitzer \& Kinney, 1989). Finally, the lifespan theory outlines a class of compensatory secondary-control strategies aimed at minimizing the motivational and emotional impact of threats to personal control—strategies further subdivided into those involving disengagement from a goal or protecting one's motivational resources. Strategies of goal disengagement involve the downgrading of a goal's importance or expectations about goal attainment. In contrast, self-protective strategies include cognitive behaviors such as positive reappraisal and strategic social comparison.

\section{Control Striving and Health in Older Adults}

According to Heckhausen and Schulz (1995; Schulz \& Heckhausen, 1996), the drive to directly engage one's environment remains constant with age (see also Heckhausen, 1997; Lachman \& Weaver, 1998; Peng, 1993; White, 1959). This motivation is evident in older adults who typically seek to maintain control over daily activities (e.g., housework; Chipperfield et al., 1999), focus on controllable aspects of restricted domains (e.g., taking medication; Affleck, Tennen, Pfeiffer, \& Fifield, 1987), and engage in new opportunities for control striving (e.g., grandparenting; Havighurst, 1952). Within Heckhausen and Schulz's (1995) framework, a 14-month longitudinal study by Wrosch et al. (2002) found goal engagement strategies (i.e., selective primary control, compensatory primary control, selective secondary control) to predict significant reductions in depressive symptomatology over a 14month period among older adults $(M=78.17$ years) experiencing relatively benign acute physical symptoms (e.g., joint pain, headache, shortness of breath).

However, as health declines begin to restrict everyday activities (Heckhausen \& Schulz, 1998; see also Baltes, 1987; Brandstädter \& Renner, 1990; Heckhausen, Dixon, \& Baltes, 1989), older adults become increasingly concerned with managing losses and sustaining basic functioning through compensatory secondary-control strategies (disengagement, self-protection). The link between such strategies, such as downgrading the importance of an unattainable goal or positive reappraisal, and optimal physical or psychological health across adulthood has been documented in several illness domains, including coronary heart disease and heart attacks (Affleck, Tennen, Croog, \& Levine, 1987), cancer (Carver et al., 1993), and HIV (Thompson, Nanni, \& Levine, 1994). Studies based on the life-span theory of control further illustrate the increasing importance of self-protection relative to engagement strategies among older adults for dealing with aging-related health declines (age 60 and older; Heckhausen, 1997), and the positive effects of self-protection strategies on subjective well-being (ages 60-76, positive reappraisal; Wrosch et al., 2000), as well as on avoiding hospitalization and longer survival in later life (age 70 and older, optimistic social comparisons; Bailis, Chipperfield, \& Perry, 2005; see also Chipperfield \& Perry, 2006).

\section{Opportunity for Control: Acute Versus Chronic Conditions}

According to the life-span theory of control, optimizing one's control striving requires engaging in control behaviors that are congruent with the opportunities afforded by a given developmental ecology (Heckhausen \& Schulz, 1998). In the health domain, the effectiveness of control strategies is assumed to be contingent upon actual opportunities for control afforded by one's health problems (Heckhausen, 1997; Wrosch et al., 2000, Wrosch \& Schulz, 2008; 2002). Consistent with this premise, research on control striving in older adults suggests that health engagement strategies are most effective for managing acute illness symptoms of a reversible or temporary nature (e.g., headaches, joint pain; Wrosch et al., 2002) and the potentially controllable corollaries of chronic conditions (e.g., medical treatment; Band \& Weisz, 1990). In contrast, health engagement strategies are often ineffective when directed toward the uncontrollable and irreversible consequences of serious health problems (e.g., Wrosch et al., 2002). Recent research on control strategy endorsement further suggests that older people with serious acute health events (heart attack, stroke) use engagement strategies less frequently than their counterparts who have not suffered acute health events (women, age 73 and older; Chipperfield et al., 2007; for a psychometric analysis of health-related control strategies in older adults, see Haynes, Heckhausen, Chipperfield, Perry, \& Newall, 2009).

Studies examining how people psychologically adapt to lowcontrol health circumstances also illustrate the importance of compensatory secondary-control strategies for dealing with chronic health conditions. For individuals with chronic conditions, control strategies involving disengagement (e.g., acceptance and HIV; Thompson et al., 1994) or self-protection (e.g., diabetes, Band \& Weisz, 1990; leukemia, Weisz, McCabe, \& Dennig, 1994; recurrent pain, Thomsen et al., 2002) have consistently been found to predict better adjustment. In addition, positive effects of selfprotective strategies have been found for individuals after serious acute health events, with positive reappraisal strategies predicting a lower risk of reinfarction and morbidity over an 8-year period in heart attack victims (Affleck, Tennen, Croog, \& Levine, 1987; see also Croog \& Levine, 1982). Recent research by Chipperfield et al. (2007) exploring how older adults respond to acute vascular events found both types of compensatory secondary-control strategies to 
be used equally as often by those who had versus had not experienced an acute event (heart attack, stroke).

\section{Capacity for Control: Young-Old Versus Old-Old Adults}

In the gerontological research literature, old-old adults (i.e., age 80 and older; Becker, 1994) are differentiated from young-old adults on the basis of functional status, health problems, and the assistance or treatment they require (e.g., Bowling \& Browne, 1991; Carlsson, Berg, \& Wenestam, 1991; Zarit, Johansson, \& Malmberg, 1995). This classification is also an effective predictor of health outcomes and mortality (e.g., Parker, Thorslund, \& Nordstrom, 1992; Rakowski \& Cryan, 1990; Wolinsky, Arnold, \& Nallapati, 1988), with advanced old age corresponding to greater health concerns due to limited physical resources (Crimmins, Hayward, \& Saito, 1996; Harris \& Associates, 1981). However, because goal engagement strategies in the health domain become less effective in later life, older adults tend to increasingly rely on disengagement from health-related goals and self-protection to preserve their motivational and physical resources (Heckhausen, 1997).

Engagement strategies can pose serious problems for old-old adults, who are more likely to overestimate their primary control capabilities and suffer more negative consequences (Brandstädter, 1992, 1999; Lang \& Heckhausen, 2001). In contrast, research suggests that young-old adults may still derive health benefits from control strategies involving effort and persistence (Wrosch et al., 2000). Studies further suggest that older adults increasingly engage in disengagement strategies because they help to preserve one's motivation in spite of progressive physical declines (Schulz, Heckhausen, \& Locher, 1991; Wrosch et al., 2000). In exploring the interaction between age and control striving in older adults, Chipperfield et al. (1999) provided empirical support for the life-span theory of control, showing engagement strategies involving selective primary control (persistence) to predict better self-rated health in young-old adults ( $<80$ years) yet poorer health among old-old counterparts ( $>80$ years). Consistent with the life-span theory, disengagement strategies (e.g., downgrading expectations) were also found to be most beneficial for health status among old-old adults.

\section{The Present Research}

The present study explored the effects of control striving for older adults with serious health conditions and, further, the extent to which the long-term effects of control strategies are moderated by the occurrence of an acute vascular event (opportunity for control) in a population already suffering from chronic health problems, as well as age (capability for control). In particular, the effects of control strategies were examined with regard to psychological well-being, physical health, and survival. Consistent with previous studies, the independent effects of selective primarycontrol and compensatory secondary-control strategies were assessed (Bailis et al., 2005; Heckhausen, 1997; Wahl et al., 2004; Wrosch et al., 2000). However, the present analyses contribute to the research literature by further distinguishing between two forms of compensatory secondary control, namely disengagement (downgrading goal importance) and self-protection strategies (pos- itive reappraisal, downward social comparisons; see Chipperfield \& Perry, 2006; Chipperfield et al., 2007; Heckhausen, 1999), thus assessing the potentially differential effects of these related approaches (cf. individual compensatory secondary-control strategies; Affleck, Tennen, Croog, \& Levine, 1987; Bailis et al., 2005; Heckhausen \& Brim, 1997).

Hypothesis 1 proposed that engagement strategies involving selective primary control should be beneficial for those facing the challenges posed by life-threatening, acute vascular events that afford some potential for improvement (heart attack, stroke; cf. Wrosch et al., 2002), yet ineffective or detrimental for those who have not experienced either acute event but nonetheless suffer from more common, irreversible chronic conditions (arthritis, heart disease). Hypothesis 2 further suggested that control strategies involving disengagement (downgrading goal importance) should benefit older adults dealing only with chronic conditions (cf. Thompson et al., 1994) and be detrimental for those having also experienced acute vascular events where recovery may be possible. However, as acute health events in later life can negatively impact motivation and emotional well-being (due to high risk of reoccurrence, disability), Hypothesis 3 also proposed that whereas control strategies involving self-protection (positive reappraisal, downward social comparison) should help older adults dealing only with chronic health problems that limit control (Weisz et al., 1994), those who further report an acute vascular event should also benefit from these strategies due to this added threat to their control striving (Affleck, Tennen, Croog, \& Levine, 1987).

Concerning the moderating influence of age (Chipperfield et al., 1999), Hypothesis 4 stated that engagement strategies should benefit young-old adults ( $<80$ years) and, conversely, be detrimental for old-old adults ( $>80$ years). Finally, Hypothesis 5 proposed that disengagement and self-protective strategies should be more beneficial among old-old compared with young-old adults (Chipperfield et al., 1999). Study hypotheses were evaluated on four outcomes including survival, health status, functional status, and psychological well-being. The measures capture highly objective (survival), moderately objective (physician-rated condition severity; self-reported functional status), and highly subjective outcomes (well-being), and consist of physiological, behavioral, and psychological health indicators. More specific hypotheses concerning differential effects across the dependent measures were not proposed due to the overarching, developmental focus of the life-span theory and previous control research in which only specific outcomes (e.g., mortality, Bailis et al., 2005) and moderating variables (e.g., age, Chipperfield et al., 1999; health condition, Wrosch et al., 2002) were explored.

\section{Method}

Our study included a subset of participants in the Aging in Manitoba (AIM) study, one of the largest existing populationbased longitudinal studies, consisting of interviews with nearly 9,000 older individuals (Chipperfield, Havens, \& Doig, 1997). AIM participants have been tracked for 35 years, making the study one of the longest continuing population-based studies of older individuals (M. Hall et al., 1997). Before we describe the relevant subset of AIM individuals selected for the present study, a brief overview of the larger AIM study follows. 


\section{The AIM Study}

The first wave of participants in the AIM study was assessed in 1971, and new waves were added to the study in 1976 and 1983. Follow-up interviews were conducted with surviving individuals at four subsequent points in time-1983, 1990, 1996, and 2001producing both cross-sectional and longitudinal data (two additional sessions were conducted in 2005 and 2006 following the completion of the present analyses). The selection of AIM subjects for each new wave involved rigorous stratified randomization techniques, resulting in probability samples stratified by age, gender, and region. These sampling procedures were successful in minimizing selection bias and selective attrition and in achieving representativeness both initially (e.g., Mossey, Havens, Roos, \& Shapiro, 1981) and at follow-up (Chipperfield et al., 1997), as illustrated by the similarity of AIM participants compared with the Manitoba population. Moreover, the modest nonresponse level in the AIM study did not erode the demographic representativeness of the surviving sample (i.e., marital status, gender; see Chipperfield et al., 1997).

\section{Successful Aging Study}

The present analyses were based upon participation in a satellite study of the larger AIM project referred to as the Successful Aging Study (SAS). The SAS occurred approximately 3 months after the 1996 AIM follow-up and consisted of a more focused study of the psychological aspects of aging (Chipperfield, Perry, Volk, \& Hladkyj, 2003). Following a review of AIM (1996) participant information, respondents were identified as ineligible for the SAS if they (a) lived outside major urban centers and surrounding areas, (b) resided in personal care homes, (c) had poor comprehension, and/or (d) were unable to respond to the AIM interview in English or without the help of a proxy. Interviewers telephoned all other eligible participants to introduce themselves, describe the overall study goals, and arrange a time for a 1.5-hr face-to-face interview to take place in the respondent's home. Of those who met the eligibility criteria (458 participants), interviews were conducted with 353 participants (77\%). Reasons for nonparticipation included participants' unwillingness $(n=72)$, illness $(n=15)$, and inability to contact $(n=18)$.

Embedded within the SAS interview were questions designed specifically to assess adaptive control strategies for dealing with restrictive health problems. Due to the study focus on identifying older individuals with acute health difficulties, participants were first asked whether they had experienced a heart attack or stroke within the past year and, if so, to what extent it had restricted their behavior. If neither acute event was reported, participants were asked whether they had experienced a chronic heart condition (e.g., hypertension) or arthritis within the past year and the degree to which that condition restricted their behavior. Individuals who reported having experienced a restrictive, acute vascular event or chronic health problem were then asked about the control strategies they used to respond to these specific health-induced restrictions (see below for specific information on this "funnel" approach).

It is important to note that because chronic health problems are extremely common in later life, the majority of older adults who reported an acute event also experienced coexisting chronic con- ditions. This comorbidity precludes the analysis of older adults who experienced an acute vascular event (heart attack, stroke) but who otherwise have had no chronic health problems. As such, the purpose of this study was to examine whether those who had experienced an acute event used different strategies to deal with the associated restrictions than those who were dealing only with chronic conditions. The initial sample included 143 individuals who responded to control strategy questions during the 1996 interview. The sample size for the follow-up AIM interview 5 years later (2001) was 35\% lower $(N=93)$ due to mortality and nonparticipation. Chi-square and $t$-test analyses showed only age, $t(141)=3.42, p=.001$, to predict AIM 2001 attrition and no evidence of disproportionate attrition as a function of control strategy levels, having experienced an acute vascular event, or background measures (gender, income, education).

\section{Independent Measures}

The independent variables in the present study were the taskspecific control strategies (TSCS), participants' age, and the occurrence of an acute vascular event (no, yes) as assessed during the SAS 1996 interview. Covariates included baseline levels of the dependent measures and demographic characteristics assessed in the AIM 1996 interview. Means, standard deviations, and observed ranges for independent measures are provided in Table 1.

Demographic variables. In terms of participants' gender, the analyses included a representative sample of 46 men and 97 women, with the higher proportion of women $(68 \%)$ reflecting their greater longevity. The mean age of individuals was over 80 years, as determined by subtracting participants' interview date from their date of birth. Education was assessed by asking respondents how many years or grades had been completed in school. Participants had between 10 and 11 years of schooling on average, and although this level of education might be regarded as low, it is quite typical for this birth cohort (e.g., $M=11.3$ years; Krause, 1998).

The measure of monthly income was derived by summing responses to a series of questions about income from a variety of sources (i.e., own resources such as private pensions, wages, rents, dividend interest; pensions and allowances such as Old Age Security, war veterans, unemployment insurance; other sources such as children, service groups, private agencies). Three extreme outliers were first identified and pulled into the distribution, while retaining their rank ordering. Next, rather than exclude participants who did not report income $(n=47)$, we used a regression-based substitution method as proposed by Tabachnick and Fidell (2001). In particular, because stepwise regression analyses revealed that participants' education and gender significantly predicted income, we estimated income for each of these 47 participants using the regression equation (i.e., intercept and regression coefficients) and the individual predictor data (i.e., education and gender). The adjusted mean monthly income was $\$ 1,261.85$ (Canadian).

Task-specific control strategies. Control striving among older adults in this study was assessed with respect to specific strategies used to deal with restrictions in daily activities regarded by the participant as being due a serious health problem of either an acute or chronic nature. The three-step funnel approach used to assess individuals' use of TSCS outlined in detail elsewhere (Chipperfield \& Perry, 2006; Chipperfield et al., 2007) is briefly sum- 
Table 1

Summary of Study Variables

\begin{tabular}{|c|c|c|c|c|c|c|}
\hline Variable & $n$ & Range & $M$ & $S D$ & Number of items & $\alpha$ \\
\hline \multicolumn{7}{|c|}{ Background measures } \\
\hline Age (years) & 143 & 73.44-97.50 & 80.80 & 5.59 & 1 & \\
\hline Gender & 143 & 46 men, 97 women & & & 1 & \\
\hline Income (dollars) ${ }^{\mathrm{a}}$ & 143 & $0-5,000$ & $1,261.85$ & 802.66 & 1 & \\
\hline Education (years) & 143 & $2-18$ & 10.27 & 2.25 & 1 & \\
\hline Acute event & 143 & 108 no, 35 yes & & & 1 & \\
\hline \multicolumn{7}{|c|}{ Task-specific control strategies } \\
\hline Engagement & 122 & $0-20$ & 11.93 & 4.16 & 5 & .72 \\
\hline Disengagement & 139 & $0-8$ & 3.53 & 2.14 & 2 & \\
\hline \multicolumn{7}{|l|}{ Self-protection } \\
\hline Positive reappraisal & 136 & $0-4$ & 2.32 & 1.26 & 1 & \\
\hline Social comparison & 140 & $0-4$ & 2.99 & 0.99 & 1 & \\
\hline \multicolumn{7}{|c|}{ Dependent measures } \\
\hline Survival (9 years) & 136 & 64 deceased, 72 alive & & & 1 & \\
\hline Health status ( 5 years) & 93 & $151-1,016$ & 742.51 & 193.13 & 22 & N/A \\
\hline Functional status ( 5 years) & 93 & $0-22$ & 15.90 & 4.91 & 22 & N/A \\
\hline Subjective well-being (5 years) & 80 & $13-24$ & 20.98 & 2.29 & 12 & .70 \\
\hline
\end{tabular}

Note. Background and control variables from 1996. Self-report dependent measures from 2001 (1996 baseline levels not reported). Survival assessed in 2005. N/A = not applicable due to checklist measure.

${ }^{a}$ Total monthly income in Canadian dollars from various sources (e.g., wages, rents, dividend interest, pensions, unemployment insurance, children, private agencies). Missing income values for 47 participants estimated through a regression-based substitution method including education and gender as predictors.

marized below and in the Appendix. Before responding to the strategy scale items, participants were asked to focus their responses on specific restricted activities they perceived to be the result of their specific serious health condition.

Step 1 of the funnel process involved the "identification of health-induced restrictions" and required participants to indicate how frequently $(0=$ never, $1=$ sometimes, $2=$ often $)$ their health condition (heart disease, arthritis, heart attack, stroke) resulted in restrictions on achievement tasks (e.g., performing day-to-day tasks), leisure activities (e.g., golf, walking), and affiliative activities (e.g., visiting friends). Step 2 involved the "identification of the domain of greatest restriction," which in almost two thirds of the cases was reported to be an achievement-related task or activity $(62.2 \%)$ relative to leisure activities $(31.5 \%)$ and affiliative activities (6.3\%). On the basis of previous findings of Chipperfield et al. (2007) showing notably few differences in control strategy use as a function of restriction type (achievement, leisure), domain of restriction was not evaluated as a moderating variable in the present analyses. Finally, in Step 3, "strategy assessment," participants were asked to focus attention on their "most restricted" task or activity and to rate how frequently, if ever, each of nine specific control strategies was used $(0=$ never, $1=$ rarely, $2=$ sometimes , 3 = often, 4 = almost always $)^{1}$

Factor analyses of five selective primary-control items showed a single factor reflecting goal engagement strategies (persistence, task modification; $\alpha=.72$; see Chipperfield \& Perry, 2006). Factor analyses on the four compensatory secondary-control items revealed two factors consisting of two items each, namely goal disengagement (downgrading perceived task importance; $r=.39$ ) and self-protection (positive reappraisal, downward social comparisons; $r=.04$ ). Following from these results, three types of control strategies were assessed including selective primary-control strat- egies (goal engagement) and compensatory secondary-control strategies involving goal disengagement and self-protection. Despite high loadings on a self-protection factor $(>.60)$, the positive reappraisal and social comparison items were evaluated separately as warranted by the nonsignificant interitem correlation. Although composite self-protection measures have been evaluated in previous studies, they typically demonstrate lower internal reliability than other strategy types (e.g., Heckhausen, Wrosch, \& Fleeson, 2001), likely due to being functionally complementary yet serving as substitutes for each other in different individuals. Consequently, the present analyses parallel those of Chipperfield and Perry (2006) in which these self-protection items were evaluated as independent predictors, with each expected to show equivalent effects on study outcomes (cf. duration of hospital stays; Chipperfield \& Perry, 2006).

Acute vascular events. A dichotomous variable $(0=n o, 1=$ yes) was created by identifying individuals who had experienced

\footnotetext{
${ }^{1}$ A previous principal-component factor analysis of the original 15 TSCS items (Chipperfield \& Perry, 2006) provided empirical justification for the classification of items as primary- or secondary-control strategies, and six scale items were omitted in the present analyses with respect to the following four-part rationale. As our analysis required a response on each strategy, two items not asked of all participants were omitted (compensatory primary control; Items 8,9 ). Two items assessing selective secondary control (Items 5, 14) were also omitted on the basis of omnibus factor analyses showing these items not to load together and to have the lowest maximum loadings (.48 and .50; Chipperfield et al., 2003). Two additional items were also deleted, one due to conceptual ambiguity ("reengagement," Item 13; see Chipperfield et al., 2007) and the other because it did not load significantly in factor analyses on the five remaining secondary-control items (downgrading personal expectations, Item 1).
} 
an acute and life-threatening vascular event $(n=35$; heart attack, stroke) as opposed to those who did not $(n=108)$. Those who did not report an acute event responded instead to TSCS items concerning more common restrictive health problems of a chronic nature (heart disease, arthritis). The majority of adults who experienced an acute vascular event had suffered a heart attack (83\%), with the remaining having suffered a stroke. The majority of adults in our study who responded to TSCS items with respect to chronic conditions reported having arthritis $(81 \%)$, with the remaining individuals reporting heart disease.

As all but one of the older adults in our study who reported experiencing an acute vascular event also lived with chronic conditions, it is important to reiterate that this dichotomous variable does not distinguish between older adults having experienced only an acute as opposed to a chronic condition. Rather, this measure represents the occurrence of an acute event among older adults who already suffer from restrictive health problems, with those reporting an acute vascular event experiencing additional health challenges. No differences as a function of acute event occurrence (no, yes) were found with regard to participants' reported use of control strategies, the recency of the condition onset or event, the number of chronic health conditions, the seriousness of those conditions, or functional status (see Chipperfield et al., 2007).

\section{Dependent Measures}

The primary dependent variable consisted of survival data obtained 9 years after the initial SAS 1996 interview. Self-report measures assessed participants' health status, functional status, and subjective well-being in the SAS 1996 and AIM 2001 interviews. Descriptive details for each dependent measure are outlined in Table 1.

Survival. At 9 years postinterview (November 2005), mortality records were obtained from an administrative health registry maintained by the Manitoba Centre for Health Policy. This registry contains data on all provincial residents covered under the universal health insurance system, capturing information on deaths that occurred during hospitalizations. Additional mortality data were obtained through government records (Department of Vital Statistics). Survival was assumed unless a death was recorded; 64 participants (44.8\%) were known to be deceased by 2005 . Because access was restricted to an indicator of survival (no, yes), exact date of death was not available. Thus we conducted subsequent survival analyses using a more conservative, dichotomous outcome $(0=$ deceased, 1 = alive $)$.

Health status. Participants' physical health status was assessed by first asking participants about the occurrence (yes, no) of 22 specified health problems or diseases encountered within the previous year: arthritis or rheumatism; palsy; problems with eyes, ears, teeth, stomach, feet, skin, and other areas; heart-related problems (e.g., hardening of the arteries, hypertension, heart attack); chest problems (e.g., emphysema, tuberculosis, breathing problems); stroke; kidney problems; and diabetes. The severity of these conditions was then evaluated on the Seriousness of Illness Rating Scale (SIRS, Wyler, Masuda, \& Holmes, 1968; SIRSRevised [SIRS-R], Rosenberg, Hayes, \& Peterson, 1987). Briefly, Wyler et al. (1968) had medical students and residents assign scores (ranks) to reflect the seriousness of 137 illnesses.
For nine of the 22 conditions having an exact match to an SIRS-R item, the corresponding scores were adopted for our severity measure. For 10 conditions having multiple near matches to SIRS-R items, we calculated an average of the corresponding SIRS-R illness scores. For three conditions with neither an exact nor near match, an average of scores assigned by two medical residents was used. A total severity score was created by summing over the severity scores that corresponded to each condition a given participant had identified (see also Chipperfield et al., 2007). This measure was subsequently inverted (i.e., subtracting each score from the combined total of the minimum and maximum severity scores) to allow for higher values to be interpreted more intuitively as better physical health.

Functional status. Functional status was determined on the basis of reported independence on basic activities of daily living and instrumental activities of daily living. Basic activities of daily living were assessed via participants' ratings of their abilities to perform basic activities that are central to daily functioning: going up and down the stairs, getting about the house, getting in and out of bed, washing or bathing or grooming, dressing and putting shoes on, eating, and so on. Instrumental activities of daily living, which, although not as basic to daily functioning, are instrumental to living independently, included activities such as doing light housework, doing heavy housework, making tea or coffee, preparing a hot meal, shoveling or yard work, shopping, managing financial matters, doing laundry, major household repairs, and taking medication or receiving treatment. An overall functional status measure was created by summing the number of basic activities of daily living and instrumental activities of daily living that the respondent was able to perform independently (1996: $\alpha=$ .96; 2001: $\alpha=.96$ ), with higher scores reflecting greater independence.

Subjective well-being. Participants' perceptions of personal well-being were measured in the 1996 interview with a life satisfaction measure (Neugarten, Havighurst, \& Tobin, 1961) summing together responses to 20 first-person statements such as "As I look back on my life, I am fairly well satisfied" $(0=$ disagree, $1=$ agree; $\alpha=.74)$. A more recent 12 -item measure of happiness was administered in the 2001 interview (Stones et al., 1996; $\alpha=.70$ ). Similar to the Neugarten et al. (1961) measure, this scale summed together six items concerning general life experiences, such as "Things are getting worse as I get older" (reverse coded), and six items asking participants how they felt over the past month, such as "generally satisfied with how your life has turned out" (yes, no). The Neugarten et al. scale assessed in 1996 was included as a covariate in subsequent analyses on the Stones et al. (1996) measure from 2001 to control for baseline levels.

\section{Data Analyses}

Regression analyses evaluated the study hypotheses regarding the effects of control strategies as moderated by an acute vascular event (Hypotheses 1-3) and age (Hypotheses 4-5). We conducted hierarchical ordinary least squares regressions for the self-report dependent measures at 5 years, and we conducted hierarchical logistic regressions for survival at 9 years using SPSS 16.0 software. In keeping with Chipperfield and Perry (2006), we assessed each control strategy separately (i.e., only one control strategy in each regression analysis) to maximize power and minimize the risk 
of Type II error due to our reduced sample size at the 5-year follow-up. ${ }^{2}$

In all regression analyses, Step 1 included the background variables of gender, education, and income and the baseline assessment for self-report outcomes. Also included in Step 1 were the independent variables of strategy, acute event, and age. To evaluate the study hypotheses, we included Strategy $\times$ Acute Event and Strategy $\times$ Age interactions in Step 2. We evaluated significant interactions using simple slopes tests at one standard deviation above or below the mean (strategy, age), with the youngold $(M-1, S D=75.21)$ versus old-old $(M+1, S D=86.39)$ distinction consistent with previous research (cf. Becker, 1994; Chipperfield et al., 1999). In keeping with our specific and empirically based hypotheses, as well as the restricted power of our survival analyses due to its dichotomous nature (cf. Bhandari, Lochner, \& Tornetta, 2002; Felson, Zhang, \& Siegel, 2008), we evaluated interaction effects and simple slopes using one-tailed significance tests.

\section{Results}

Hierarchical regression results are presented for engagement, downgrading, and self-protection (positive reappraisal) in Table 2. Predicted values and significant simple slopes contrasts for all significant interactions are provided in Tables 3 and $4 .^{3}$

\section{Goal Engagement}

A significant interaction between goal engagement strategies and acute event occurrence on survival was observed $(O R=-.64$, $p<.05$; see Figure 1A). Consistent with Hypothesis 1 , older adults who more frequently used selective primary-control strategies to deal with task difficulties caused by acute vascular events were $39 \%$ more likely to be alive 9 years later than their counterparts who used these strategies less frequently. This interaction was also significant for health status $(\beta=.14, p=.05)$. As outlined in Table 3, older adults who more frequently used engagement strategies for tasks not restricted by acute events, but instead by more common chronic conditions, reported poorer physical health than those who used engagement strategies less frequently. Significant interactions between engagement and age were also observed on health status $(\beta=-.27, p<.01$; see Figure $1 \mathrm{~B})$ as well as functional status $(\beta=-.28, p<.05)$. Consistent with Hypothesis 4 , greater use of engagement strategies was found to predict poorer physical health and functional status 5 years later specifically for old-old adults.

\section{Goal Disengagement}

A significant interaction between disengagement and acute event occurrence was found on health status $(\beta=-.20, p<.01)$. As proposed in Hypothesis 2, greater use of strategies involving the downgrading of goal importance predicted better physical health 5 years later for older adults dealing with task challenges resulting from common chronic conditions. In contrast, for those having also experienced an acute vascular event, a high level of disengagement corresponded to poorer physical health 5 years later (see Figure 2). The Disengagement $\times$ Age interaction was also significant for health status $(\beta=.16, p<.05)$. Consistent with Hypothesis 5, higher levels of disengagement were found to predict better physical health 5 years later only for old-old adults (see Table 4). Hence, inverse and thus complementary findings were observed for engagement and disengagement strategies on participants' health status, with goal engagement being detrimental for old-old adults and downward adjustment proving beneficial for old-old individuals.

\section{Self-Protection: Positive Reappraisal}

Analyses of the social comparison strategy revealed no significant main or interaction effects on the four outcome measures ( $p<.05$; age main effects similar to other regressions). In contrast, significant Strategy $\times$ Acute Event interactions were observed for the positive reappraisal strategy on each dependent measure. For the sake of parsimony, only the regression findings for positive reappraisal are presented in Table 3. As shown in Figure 3A, partial support was found for Hypothesis 3, with higher levels of positive reappraisal predicting a $24 \%$ greater likelihood of survival 9 years later among those reporting an acute vascular event $(O R=-.72, p<.05)$. Positive reappraisal was also found to predict higher levels of health status $(\beta=.22, p<.01$; see Figure $3 \mathrm{~B})$, functional status $(\beta=.18, p<.05)$, and subjective well-being 5 years later $(\beta=.26, p<.01)$ only among those who had experienced an acute vascular event. Finally, a significant interaction between positive reappraisal and age, as predicted by Hypothesis 5, was observed on functional status $(\beta=.18, p<$ $.05)$, showing greater use of positive reappraisal strategies to predict better functional status 5 years later specifically for old-old adults.

\section{Discussion}

Consistent with previous research on health and aging based on the life-span theory of control (Heckhausen \& Schulz, 1995, 1998; Schulz \& Heckhausen, 1996), the present study provides empirical support for the long-term benefits and risks of goal engagement,

\footnotetext{
${ }^{2}$ The independent analysis of TSCS measures follows from both correlations and rules of thumb concerning participant-to-predictor ratios. First, correlations between TSCS measures were not significant, supporting their analysis as orthogonal constructs. Second, whereas a 10:1 ratio is often endorsed as the absolute minimum participant-to-predictor ratio, this standard underestimates the sample required to evaluate individual predictors as opposed to $R^{2}$ (Maxwell, 2000). The present analyses on our critical survival outcome are instead consistent with a more conservative ratio of 15:1 recommended for social sciences research (Stevens, 2002) in including up to nine predictors (see Footnote 3 ) for 136 participants (see Table 1).

${ }^{3}$ Supplemental hierarchical logistic regressions on survival for each TSCS strategy were conducted in which several variables from the SAS 1996 interview were iteratively included as potentially confounding baseline covariates in Step 1. The background variables included self-report measures of physical health (global item, condition severity), activity level (energy item, functional status), psychological well-being (life satisfaction), and caregiving support (home care, nursing, cohabitation). Results showed the Engagement $\times$ Acute Event interaction (odds ratio range: .60-.67) and Positive Reappraisal $\times$ Acute Event interaction (odds ratio range: .68-.75) to remain statistically significant in each analysis, underscoring the robust nature of subsequent findings for survival in which no baseline measure was controlled for.
} 
Table 2

Hierarchical Regression Results by Control Strategy

\begin{tabular}{|c|c|c|c|c|}
\hline Predictor & Survival & Health status & Functional status & Subjective well-being \\
\hline \multicolumn{5}{|c|}{ Engagement } \\
\hline \multicolumn{5}{|l|}{ Step 1} \\
\hline Baseline & & $.59^{* * *}$ & $.27^{*}$ & $.25^{*}$ \\
\hline Gender & -1.12 & .15 & -.09 & .01 \\
\hline Income & -0.93 & .04 & .08 & $.25^{*}$ \\
\hline Education & $-1.57^{*}$ & .12 & $.22^{*}$ & -.04 \\
\hline$R^{2}$ & .06 & .41 & .16 & .14 \\
\hline \multicolumn{5}{|l|}{ Step 2} \\
\hline Age & $-1.99^{* *}$ & $-.36^{* *}$ & $-.36^{* *}$ & -.17 \\
\hline Strategy & -0.91 & -.17 & -.10 & -.10 \\
\hline Acute event ${ }^{\mathrm{a}}$ & -1.35 & -.03 & .09 & .09 \\
\hline$R^{2}$ & $.19^{* * *}$ & $.53^{* *}$ & $.28^{* * *}$ & .18 \\
\hline \multicolumn{5}{|l|}{ Step 3} \\
\hline Strategy $\times$ Acute Event & $-0.64^{*}$ & $.14^{*}$ & .14 & .01 \\
\hline Strategy $\times$ Age & -1.02 & $-.27^{* *}$ & $-.28^{*}$ & .01 \\
\hline$R^{2}$ & .23 & $.59^{* *}$ & $.34^{*}$ & .18 \\
\hline \multicolumn{5}{|c|}{ Disengagement } \\
\hline \multicolumn{5}{|l|}{ Step 2} \\
\hline Age & $-1.78^{* * *}$ & $-.21^{* *}$ & $-.28^{* *}$ & -.11 \\
\hline Strategy & -0.96 & .03 & .09 & -.02 \\
\hline Acute event ${ }^{\mathrm{a}}$ & -1.20 & .06 & .10 & .18 \\
\hline$R^{2}$ & .15 & .46 & .42 & .18 \\
\hline \multicolumn{5}{|l|}{ Step 3} \\
\hline Strategy $\times$ Acute Event & -0.89 & $-.20^{* *}$ & -.10 & -.03 \\
\hline Strategy $\times$ Age & -1.09 & $.16^{*}$ & .12 & -.15 \\
\hline$R^{2}$ & .15 & $.52^{* *}$ & .44 & .20 \\
\hline \multicolumn{5}{|c|}{ Self-protection } \\
\hline \multicolumn{5}{|l|}{ Step 2} \\
\hline Age & $-1.75^{* *}$ & -.16 & $-.20^{*}$ & -.09 \\
\hline Strategy & -1.05 & .11 & .04 & .07 \\
\hline Acute event $\mathrm{a}^{\mathrm{a}}$ & -1.16 & .05 & .06 & .17 \\
\hline$R^{2}$ & .14 & .45 & .40 & .19 \\
\hline \multicolumn{5}{|l|}{ Step 3} \\
\hline Strategy $\times$ Acute Event & $-0.72^{*}$ & $.22^{* * *}$ & $.18^{*}$ & $.26^{* * *}$ \\
\hline Strategy $\times$ Age & -1.22 & .07 & $.18^{*}$ & .08 \\
\hline$R^{2}$ & .17 & $.49^{*}$ & .44 & .25 \\
\hline
\end{tabular}

Note. Step 1 values for the disengagement and positive reappraisal analyses were highly similar to those for the engagement analyses and are not presented. Nagelkerke $R^{2}$ values and adjusted odds ratios provided for logistic regressions on survival. Standardized $\beta$ coefficients and $R^{2}$ values provided for regressions on self-report measures. Regression coefficient and ratio values are for the step in which they were first entered. Significance of $R^{2}$ values indicates two-tailed significance of change from previous step. Main effects for strategy and acute event, and two-way interactions in social comparison regressions, are not significant at $p<.05$ and not presented. Self-protection $=$ positive reappraisal only.

${ }^{a}$ Acute event: $0=$ no, $1=$ yes.

${ }^{*} p \leq .05$. ${ }^{* *} p \leq .01$.

disengagement, and self-protection strategies for dealing with serious health problems in later life. Similar to earlier studies illustrating the differential effectiveness of control strategies based on the opportunities for health-related control (e.g., Wrosch et al., 2002), this study found the impact of each control strategy among older adults with chronic health problems to be moderated by the occurrence of an acute vascular event. More specifically, the present findings extend upon earlier work showing the benefits of goal engagement strategies for older adults with acute, temporary, and reversible health problems (e.g., Wrosch et al., 2002) by also demonstrating the effective nature of self-protection (positive reappraisal) for those having experienced an acute health crisis and of goal disengagement for those responding to more common, irreversible chronic conditions. Moreover, these findings reinforce the importance of age-related differences among older adults in the effects of health-related control striving, as found in previous control research on the moderating role of age in older populations (e.g., Chipperfield et al., 1999).

\section{Hypotheses 1-3: Acute Vascular Events}

Empirical research consistent with Heckhausen and Schulz's (1995) life-span theory suggests that health engagement strategies are optimal for dealing with acute health challenges affording 
Table 3

Predicted Values for Significant Strategy $\times$ Acute Event Interactions

\begin{tabular}{|c|c|c|c|c|}
\hline \multirow[b]{2}{*}{ Outcome } & \multicolumn{2}{|c|}{ No acute event } & \multicolumn{2}{|c|}{ Acute event } \\
\hline & Low strategy & High strategy & Low strategy & High strategy \\
\hline \multicolumn{5}{|l|}{ Engagement } \\
\hline Survival & $60.31^{\mathrm{b}}$ & 50.60 & $25.19^{\mathrm{a}, \mathrm{b}}$ & $64.55^{\mathrm{a}}$ \\
\hline Health status & $770.40^{\mathrm{a}}$ & $621.80^{\mathrm{a}}$ & 694.14 & 674.49 \\
\hline \multicolumn{5}{|l|}{ Disengagement } \\
\hline Health status & $660.00^{\mathrm{a}, \mathrm{b}}$ & $734.80^{\mathrm{a}}$ & $777.68^{\mathrm{a}, \mathrm{b}}$ & $671.63^{\mathrm{a}}$ \\
\hline \multicolumn{5}{|l|}{ Self-protection } \\
\hline Survival & $61.08^{\mathrm{b}}$ & 48.09 & $31.05^{\mathrm{b}}$ & 54.68 \\
\hline Health status & 701.10 & $707.00^{\mathrm{b}}$ & $619.63^{\mathrm{a}}$ & $814.31^{\mathrm{a}, \mathrm{b}}$ \\
\hline Functional status & 15.45 & $15.55^{\mathrm{b}}$ & $13.89^{\mathrm{a}}$ & $17.73^{\mathrm{a}, \mathrm{b}}$ \\
\hline Subjective well-being & 20.73 & $20.52^{\mathrm{b}}$ & $19.99^{\mathrm{a}}$ & $22.55^{\mathrm{a}, \mathrm{b}}$ \\
\hline
\end{tabular}

Note. All values are based on interactions from the step in which they were first entered and evaluated at one standard deviation above or below the mean (strategy). Values are adjusted for covariates including gender, education, income, and baseline levels (self-report measures), as well as main and interaction effects (see Table 2). Survival values are probabilities obtained from an antilogit transformation of predicted logit values. Self-protection $=$ positive reappraisal only.

${ }^{a}$ A priori simple slope contrast for strategy within the specified acute event level (no, yes) significant at $p \leq .05 .{ }^{\mathrm{b}}$ A priori simple slope contrast for acute event within the specified strategy level (low, high) significant at $p \leq .05$.

some degree of improvement. Conversely, engagement strategies are assumed to be ineffective or detrimental when directed toward chronic conditions with little potential for remediation (e.g., Wrosch et al., 2002). Consistent with Hypothesis 1, a two-way interaction on survival showed the effects of goal engagement to be moderated by the occurrence of an acute health event among older adults. More specifically, among older adults who had experienced a life-threatening, acute vascular event (heart attack, stroke), those who reported higher selective primary-control strategy levels (persistence, task modification) had a 39\% greater likelihood of survival than those with lower primary-control levels. In other words, among older adults coping with an acute vascular event, those who less frequently used goal engagement strategies had over twice the risk of mortality 9 years later relative to their high-engagement counterparts. In addition, the engagement regres- sion predicted considerably more variance in survival than the regressions for other control strategies on this outcome, further underscoring the significance of this effect.

These results provide further empirical support for Hypothesis 1 in suggesting that engagement strategies can also have adverse effects on older adults dealing primarily with chronic health problems (arthritis, heart disease). As indicated by a two-way interaction on health status, older adults who more frequently used selective primary-control strategies to deal with the restrictions caused by ubiquitous chronic health problems experienced less serious health conditions 5 years later compared with their counterparts who used these strategies less frequently. The significance of this finding is reinforced by this interaction having been observed despite controlling for a highly significant baseline covariate. Further, older adults who relied on engagement strategies to

Table 4

Predicted Values for Significant Strategy $\times$ Age Interactions

\begin{tabular}{lccccc}
\hline & \multicolumn{2}{c}{ Young-old } & & \multicolumn{2}{c}{ Old-old } \\
\cline { 2 - 3 } \cline { 5 - 6 } \multicolumn{1}{c}{ Outcome } & Low strategy & High strategy & & Low strategy & High strategy \\
\hline Engagement & & & & \\
$\quad$ Health status & 756.52 & $788.11^{\mathrm{b}}$ & & $746.97^{\mathrm{a}}$ & $481.22^{\mathrm{a}, \mathrm{b}}$ \\
$\quad$ Functional status & 16.84 & $18.14^{\mathrm{b}}$ & & $16.63^{\mathrm{a}}$ & $11.06^{\mathrm{a}, \mathrm{b}}$ \\
Disengagement & $777.69^{\mathrm{b}}$ & 737.94 & & $599.98^{\mathrm{a}, \mathrm{b}}$ & $700.81^{\mathrm{a}}$ \\
$\quad$ Health status & $17.09^{\mathrm{b}}$ & 16.23 & & $13.05^{\mathrm{a}, \mathrm{b}}$ & $15.94^{\mathrm{a}}$ \\
Self-protection & & & & \\
$\quad$ Functional status & & &
\end{tabular}

Note. All values are based on interactions from the step in which they were first entered and evaluated at one standard deviation above or below the mean (strategy, age). Simple slopes contrasts for age corresponded to the common differentiation between young-old $(M-1, S D=75.21)$ and old-old adults $(M+1, S D=86.39)$. Values are adjusted for covariates including gender, education, income, and baseline levels (self-report measures), as well as main and interaction effects (see Table 2). Self-protection = positive reappraisal only. ${ }^{a}$ A priori simple slope contrast for strategy within the specified age group (young-old, old-old) significant at $p \leq .05 .{ }^{\mathrm{b}}$ A priori simple slope contrast for age within the specified strategy level (low, high) significant at $p \leq .05$. 
deal with restrictions caused by chronic conditions also reported lower health status 5 years later than those who had also experienced an acute vascular event (regardless of their engagement strategy use). This finding is of interest considering that older adults experiencing both chronic and acute health challenges would reasonably be expected to demonstrate poorer health outcomes relative to those dealing only with chronic conditions.

In contrast to health engagement strategies, the life-span theory also suggests that secondary-control strategies that compensate for reduced control potential should be effective for individuals dealing with health challenges in later life due to their motivational impact (Heckhausen, 1997; Heckhausen \& Schulz, 1995). More specifically, Hypothesis 2 proposed that disengagement strategies involving downgrading should help older adults facing health challenges that are not acute but rather chronic and debilitating in nature. Conversely, poorer outcomes were anticipated for those with acute conditions because of potential adverse effects on recovery efforts. Our results support this hypothesis in showing disengagement strategy use (downward adjustment of perceived importance) concerning activities restricted only by chronic illness to predict better health status levels 5 years later. In contrast, older adults who used disengagement to cope with acute
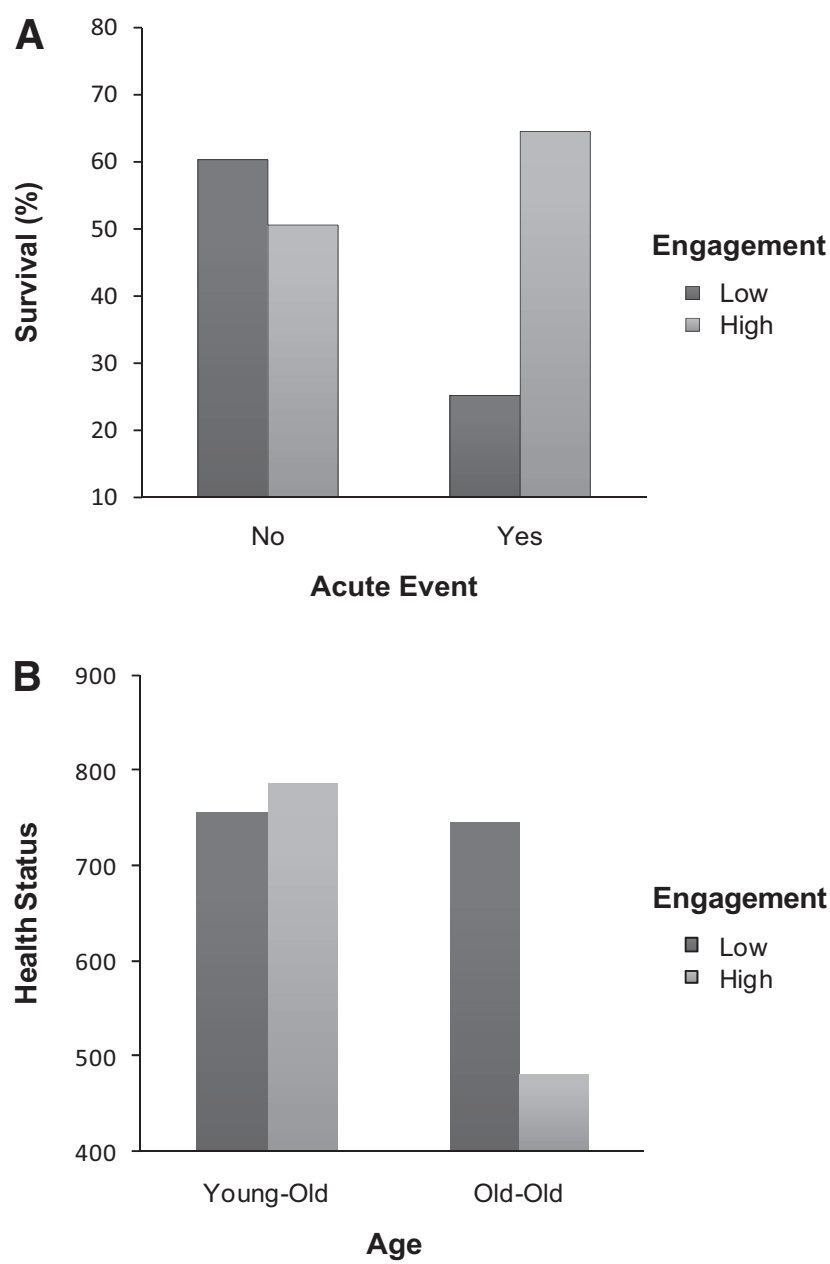

Figure 1. (A) Engagement by acute event on probability of survival at 9 years. (B) Engagement by age on health status at 5 years.

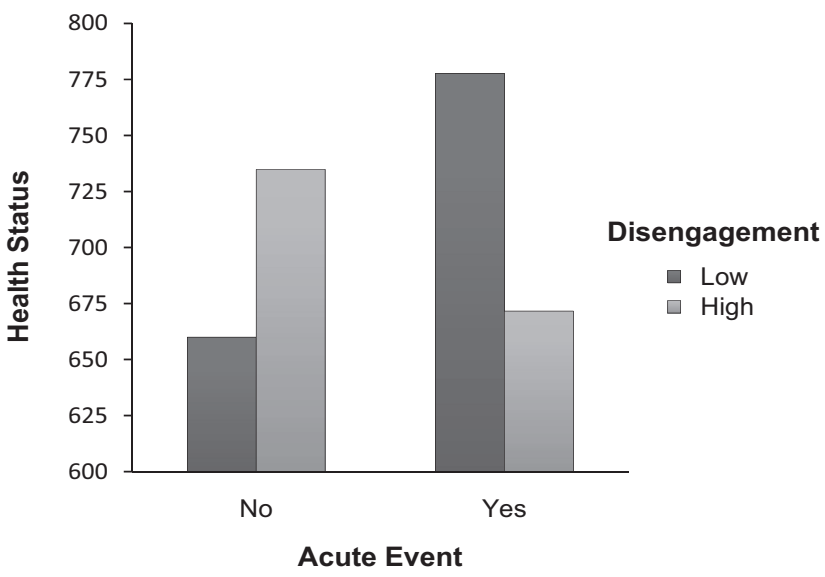

Figure 2. Disengagement by acute event on health status at 5 years.

vascular events experienced poorer health status. This suggests that although disengagement may help those dealing primarily with chronic conditions by preventing the unnecessary investment of limited physical and psychological resources in increasingly controllimiting domains, this strategy may pose a health risk when used to cope with acute conditions that are potentially reversible (e.g., through medication or rehabilitation). ${ }^{4}$

Despite the potential for remediation afforded by acute events, health crises in later life can also threaten motivation and emotional well-being due to heightened risks of reoccurrence and long-term impairment (e.g., paralysis, disability). To this end, Hypothesis 3 suggested that compensatory secondary-control strategies involving self-protection should benefit older adults coping mainly with chronic conditions that limit control striving (Weisz et al., 1994), as well as those facing acute health events that threaten health-related motivation (Affleck, Tennen, Croog, \& Levine, 1987). This study provides partial support for this hypothesis in that benefits were observed for positive reappraisal and not for social comparison strategies (see also Chipperfield \& Perry, 2006). Further, although nonsignificant interactions with acute event occurrence were hypothesized, two-way interactions showed positive reappraisal to benefit only older adults coping with an acute vascular event. As shown in Tables 2 and 3, greater positive reappraisal predicted greater levels of survival, health status, functional status, and psychological well-being specifically for those reporting an acute health crisis.

In other words, older adults who endorsed positive reappraisal as a self-protective strategy for coping with the threat of a traumatic health event had significantly higher ratings on each study indicator of physical health and psychological well-being compared with those who did not. Consistent with the life-span theory (Heckhausen, 1997; Wrosch et al., 2000), the range of significant and highly consistent effects observed for this self-protective strategy suggests that this approach is especially beneficial for physical

\footnotetext{
${ }^{4}$ The opposite pattern of interactions with age for the engagement and disengagement measures may also imply that these measures are best examined as a single composite variable. However, these control strategies were not significantly correlated, $r(120)=.06, n s$, and loaded on separate factors in a previous omnibus factor analysis (Chipperfield \& Perry, 2006), supporting the analysis of these constructs as discrete measures.
} 

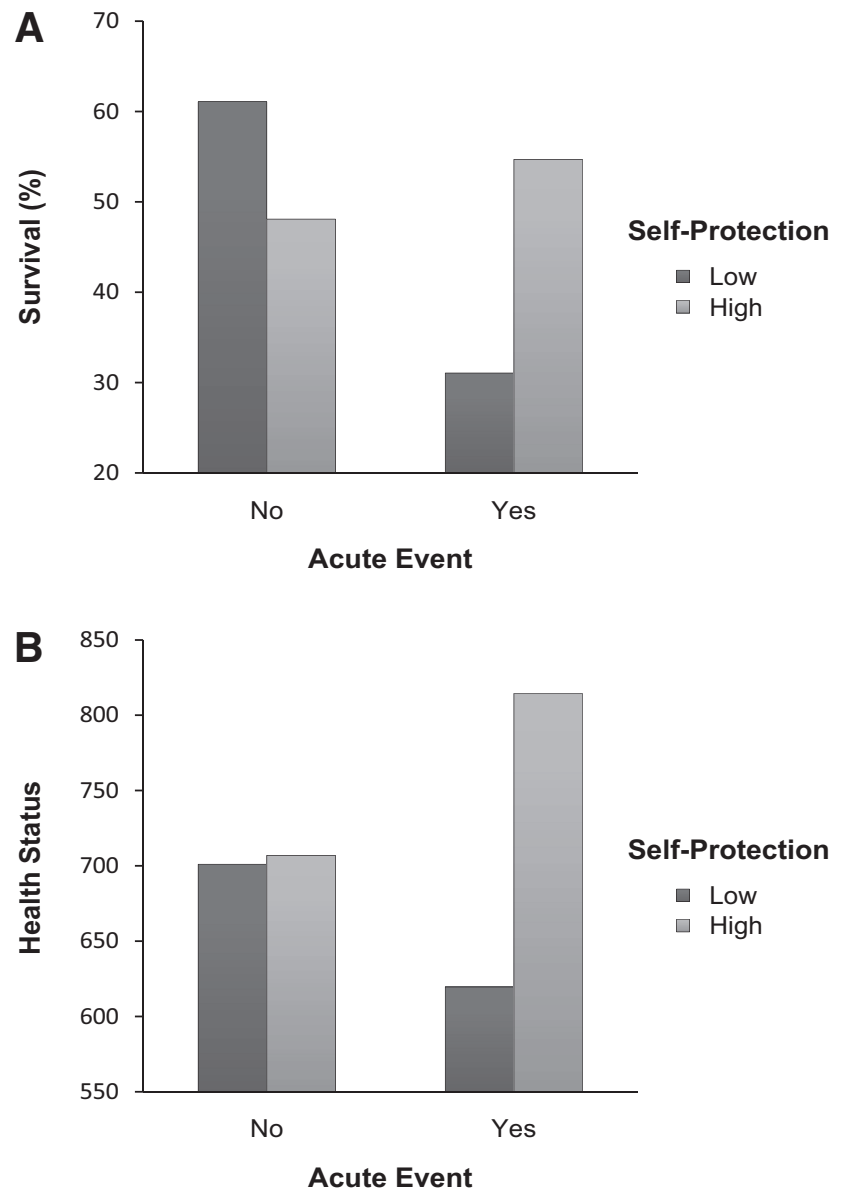

Figure 3. (A) Self-protection (positive reappraisal) by acute event on probability of survival at 9 years. (B) Self-protection (positive reappraisal) by acute event on health status at 5 years.

and psychological health among older adults in responding to an acute vascular event. ${ }^{5}$ In addition to contributing to greater longevity (albeit to a lesser extent than engagement), positive reappraisal was found to predict better levels on quality-of-life indicators including physical health, functional status, and subjective well-being for older adults with serious, acute health difficulties. In contrast, self-protective strategies did not positively impact health outcomes for those coping only with chronic conditions.

According to the life-span theory, the benefits of self-protection on objective outcomes result primarily from goal engagement behaviors afforded by sustained motivation (N. C. Hall, 2008). Thus, it is perhaps not surprising that if engagement strategies are ineffective for older adults dealing mainly with chronic and irreversible health problems, the more distal impact of self-protective strategies would also be ineffective. Nonetheless, despite an assumed direct link between self-protection and subjective wellbeing, this relationship was also not significant for those suffering primarily from chronic conditions. A possible explanation is that these strategies require significant cognitive effort and may be better suited to those coping with temporally limited acute events as opposed to indefinite and degenerative chronic health problems.

\section{Hypotheses 4-5: Young-Old Versus Old-Old Adults}

The life-span theory of control suggests that older adults increasingly rely on disengagement to avoid depleting motivational resources that are sorely needed for dealing with threats to primary control due to health problems (Schulz et al., 1991; Wrosch et al., 2000). Previous studies further indicate that goal engagement strategies can have opposite effects for young-old (positive) versus old-old adults (negative; Hypothesis 4) and, conversely, that disengagement and selfprotection strategies should benefit mainly old-old adults (Hypothesis 5; Chipperfield et al., 1999). Our findings are consistent with these hypotheses in showing that among old-old adults, goal engagement predicted poorer physical health in terms of the severity of health conditions as well as functional status. In contrast, the opposite pattern was observed for compensatory secondary-control strategies involving downgrading or self-protection (positive reappraisal), with these strategies predicting better health status and functional status levels for old-old adults, respectively. These findings suggest that similar to older individuals with acute health challenges, old-old adults represent a particularly vulnerable population for whom the long-term health benefits of disengagement (downgrading perceived importance) and self-protection (positive reappraisal), and risks of engagement strategies, are more pronounced.

\section{Study Limitations}

With respect to study limitations, it is possible that attrition and the use of self-report measures may limit the replicability of our findings on the 5-year outcomes. Future larger scale research evaluating more objective indicators of physical and psychological health (i.e., physician reports) and health behaviors (i.e., health care utilization) is warranted. Replication studies with larger samples would also permit more powerful analyses allowing for strategies to be evaluated simultaneously (greater protection against Type I error) and greater confidence in conclusions regarding specific strategy by event-age combinations (e.g., low engagement-acute event group for survival). An additional issue concerns the unavoidable confound of comorbid chronic conditions such that older adults who experience an acute event may not be able to reliably attribute functional restrictions as due to the event (e.g., heart attack) or underlying chronic illness (e.g., heart disease). Studies in which physicians (rather than individuals) determine the health condition responsible for one's restrictions, or "younger" older adults not reporting chronic conditions are assessed (e.g., ages 60-70), could more clearly elucidate the effects of control strategies in response to restrictions caused specifically by acute health events.

It should also be noted that because our study focused only on older adults who reported substantial restrictions due to major health problems and were not suffering from cognitive impairment, some find-

\footnotetext{
${ }^{5}$ According to Heckhausen and Schulz (1998), because "compensatory secondary control buffers the potential negative effects of failure on the motivational resources of the individual, and thus promotes the long-term potential for primary control" (p. 57), it is possible that self-protective strategies were beneficial because they not only allowed older adults to preserve their motivational resources but subsequently allowed them to eventually reengage in primary-control striving in the previously restricted domain (e.g., achievement) or another area of interest (e.g., affiliation; see Wrosch, Scheier, Miller, Schulz, \& Carver, 2003).
} 
ings may not generalize to older adults with fewer health restrictions or declining cognitive functioning. For example, although engagement strategies were not especially beneficial for young-old adults, these strategies do correspond to better health among older adults reporting minor difficulties with daily activities (Chipperfield et al., 1999) or temporary illness symptoms (Wrosch et al., 2002). Similarly, caution is recommended in applying these results to "younger" older adults having a greater capacity to exert control over their health circumstances (cf. ages 60-76; Wrosch et al., 2000). Further, as the present sample included only urban and community-dwelling participants, our findings may not generalize to older adults in rural areas or institutional settings (e.g., assisted care facilities, hospitals).

\section{Implications and Future Directions}

In addition to the demonstrated effects of control striving on health, well-being, and survival in later life, these findings have significant financial and intervention-related implications. Selfprotective strategies were found to predict higher levels of health and functional status among older adults who had experienced an acute vascular event-critical physical health indicators linked to older adults' use of health care services. This suggests that older individuals who use self-protective strategies to respond to health crises are less likely to require physician visits, hospitalization, and surgery, as well as assistive devices, transportation, and living arrangements. This lower use of health care services should, in turn, translate into financial savings, particularly for older adults with limited health insurance (for estimated savings due to shorter hospital stays, see Chipperfield \& Perry, 2006; cf. costs of acute postoperative medication, Dalton et al., 2000).

The present study also provides empirical support for the development of motivational interventions for older adults facing serious health challenges. Consistent with studies showing goal engagement interventions to improve motivation among young-old adults undergoing physical rehabilitation (ages 61-79; Weinberg, 2001) and health behavior among sedentary older adults (mean age $=77$; Sarkisian, Prohaska, Davis, \& Weiner, 2007), our findings indicate that engagement-focused interventions may also contribute to greater longevity among older adults following acute health events (e.g., heart attack, stroke, injury, infection). Conversely, our results suggest that interventions in which disengagement is encouraged (i.e., downward adjustment of task importance) and goal engagement is discouraged should lead to better physical health among older adults with restrictive chronic conditions (e.g., heart disease, arthritis, multiple sclerosis, emphysema) or old-old adults faced with increasingly limited capabilities.

Interventions that encourage self-protection strategies may also prove effective for older adults with acute health problems as suggested by findings showing only positive reappraisal to bolster health outcomes (as opposed to buffer losses), have no adverse effects, and positively predict each study outcome for older adults who had experienced an acute vascular event. Interventions that promote positive reappraisal or benefit finding (cf. Affleck, Tennen, Croog, \& Levine, 1987) among older adults facing acute health crises should contribute to greater longevity, physical health, and quality of life as indicated by functional status and emotional well-being. Moreover, interventions endorsing both engagement and positive reappraisal strategies for dealing with health crises may prove most effective in older populations (cf. N. C. Hall, Perry, Chipperfield, Clifton, \&
Haynes, 2006; Weisz, Thurber, Sweeney, Proffitt, \& LeGagnoux, 1997). In sum, the present study offers longitudinal evidence of the benefits and risks of control striving in later life as a function of acute vascular events and age, and provides a theoretically consistent empirical basis for interventions aimed at improving survival, physical health, and psychological well-being among older adults with serious health problems.

\section{References}

Affleck, G., Tennen, H., Croog, S., \& Levine, S. (1987). Causal attribution, perceived benefits, and morbidity after a heart attack: An 8-year study. Journal of Consulting and Clinical Psychology, 55, 29-35. doi:10.1037/ 0022-006X.55.1.29

Affleck, G., Tennen, H., Pfeiffer, C., \& Fifield, J. (1987). Appraisals of control and predictability in adapting to chronic disease. Journal of Personality and Social Psychology, 53, 273-279. doi:10.1037/00223514.53.2.273

Bailis, D. S., Chipperfield, J. G., \& Perry, R. P. (2005). Optimistic social comparisons of older adults low in primary control: A prospective analysis of hospitalization and mortality. Health Psychology, 24, 393401. doi:10.1037/0278-6133.24.4.393

Baltes, P. B. (1987). Theoretical propositions of life-span developmental psychology: On the dynamics between growth and decline. Developmental Psychology, 23, 611-626. doi:10.1037/0012-1649.23.5.611

Baltes, P. B., \& Baltes, M. M. (1990). Successful aging: Perspectives from the behavioral sciences. New York, NY: Cambridge University Press.

Band, E. B., \& Weisz, J. R. (1990). Developmental differences in primary and secondary control coping and adjustment to juvenile diabetes. Journal of Clinical Child Psychology, 19, 150-158. doi:10.1207/ s15374424jccp1902_7

Becker, G. (1994). The oldest old: Autonomy in the face of frailty. Journal of Aging Studies, 8(1), 59-76. doi:10.1016/0890-4065(94)90019-1

Bhandari, M., Lochner, H., \& Tornetta, P., III. (2002). Effect of continuous versus dichotomous outcome variables on study power when sample sizes of orthopaedic randomized trials are small. Archives of Orthopaedic and Trauma Surgery, 122, 96-98. doi:10.1007/s004020100347

Bowling, A., \& Browne, P. D. (1991). Social networks, health, and emotional well-being among the oldest old in London. Journal of Gerontology, 46(1), S20-S32.

Brandstädter, J. (1992). Personal self-regulation of development: Crosssequential analyses of development-related control beliefs and emotions. Developmental Psychology, 25, 96-108. doi:10.1037/00121649.25.1.96

Brandstädter, J. (1999). Sources of resilience in the aging self: Toward integrating perspectives. In T. M. Hess \& F. Blanchard-Fields (Eds.), Social cognition and aging (pp. 123-141). San Diego, CA: Academic Press. doi:10.1016/B978-012345260-3/50007-0

Brandstädter, J., \& Renner, G. (1990). Tenacious goal pursuit and flexible goal adjustment: Explication and age-related analysis of assimilative and accommodative strategies of coping. Psychology and Aging, 5, 58-67. doi:10.1037/0882-7974.5.1.58

Carlsson, M., Berg, S., \& Wenestam, C. (1991). The oldest old: Patterns of adjustment and life experiences. Scandinavian Journal of Caring Sciences, 5(4), 203-210.

Carver, C. S., Pozo, C., Harris, S. D., Noriega, V., Scheier, M. F., Robinson, D. S., . . Clark, K. C. (1993). How coping mediates the effect of optimism on distress: A study of women with early stage breast cancer. Journal of Personality and Social Psychology, 65, 375-390. doi:10.1037/0022-3514.65.2.375

Chipperfield, J. G., Havens, B., \& Doig, W. (1997). Methods and description of the Aging in Manitoba Project: A 20-year longitudinal study. Canadian Journal on Aging, 16(4), 606-625.

Chipperfield, J. G., \& Perry, R. P. (2006). Primary- and secondary-control 
strategies in later life: Predicting hospital outcomes in men and women. Health Psychology, 25(2), 226-236. doi:10.1037/0278-6133.25.2.226

Chipperfield, J. G., Perry, R. P., Bailis, D. S., Ruthig, J. C., \& Chuchmach, L. P. (2007). Gender differences in use of primary and secondary control strategies in older adults with major health problems. Psychology and Health, 22(1), 83-105. doi:10.1080/14768320500537563

Chipperfield, J. G., Perry, R. P., \& Menec, V. H. (1999). Primary and secondary control-enhancing strategies: Implications for health in later life. Journal of Aging and Health, 11, 517-539. doi:10.1177/ 089826439901100403

Chipperfield, J. G., Perry, R. P., Volk, J., \& Hladkyj, S. (2003). The Successful Aging Study (1996): Description and methods (Tech. Rep. No. HLHPRI103). Winnipeg, Canada: University of Manitoba, Health, Leisure and Human Performance Research Institute.

Crimmins, E. M., Hayward, M. D., \& Saito, Y. (1996). Differentials in active life expectancy in the older population of the United States. Journals of Gerontology: Series B. Psychological Sciences and Social Sciences, 51(3), S111-S120.

Croog, S. H., \& Levine, S. (1982). Life after a heart attack: Social and psychological factors eight years later. New York, NY: Human Sciences Press.

Dalton, J. A., Carlson, J., Lindley, C., Blau, W., Youngblood, R., \& Greer, S. M. (2000). Clinical economics: Calculating the cost of acute postoperative pain medication. Journal of Pain and Symptom Management, 19(4), 295-308. doi:10.1016/S0885-3924(00)00105-6

Felson, D. T., Zhang, B., \& Siegel, J. N. (2008). Trials in rheumatoid arthritis: Choosing the right outcome measure when minimal disease is achievable. Annals of the Rheumatic Diseases, 67, 580-583. doi: 10.1136/ard.2007.079632

Gollwitzer, P. M., \& Kinney, R. F. (1989). Effects of deliberative and implemental mind-sets on illusion of control. Journal of Personality and Social Psychology, 56, 531-542. doi:10.1037/0022-3514.56.4.531

Hall, M., Havens, H., Black, C., Carrier, K. C., Chipperfield, J. G., Kyle, B., ... Shapiro, E. (1997). Aging in Manitoba 1996: A 25-year longitudinal study [Tech. rep.], Winnipeg, Canada: Department of Community Health Sciences.

Hall, N. C. (2008). Self-regulation of primary and secondary control in achievement settings: A process model. Journal of Social and Clinical Psychology, 27(10), 1126-1164. doi:10.1521/jscp.2008.27.10.1126

Hall, N. C., Perry, R. P., Chipperfield, J. G., Clifton, R. A., \& Haynes, T. L. (2006). Enhancing primary and secondary control in achievement settings through writing-based attributional retraining. Journal of Social and Clinical Psychology, 25, 361-391. doi:10.1521/jscp.2006.25.4.361

Harris, L., \& Associates. (1981). Aging in the eighties: America in transition. Washington, DC: National Council on the Aging.

Havighurst, R. J. (1952). Developmental tasks and education (2nd ed.). New York, NY: McKay.

Haynes, T. L., Heckhausen, J., Chipperfield, J. G., Perry, R. P., \& Newall, N. E. (2009). Primary and secondary control strategies: Implications for health and well-being among older adults. Journal of Social and Clinical Psychology, 28, 165-197. doi:10.1521/jscp.2009.28.2.165

Heckhausen, J. (1997). Developmental regulation across adulthood: Primary and secondary control of age-related challenges. Developmental Psychology, 33, 176-187. doi:10.1037/0012-1649.33.1.176

Heckhausen, J. (1999). Developmental regulation in adulthood: Agenormative and sociostructural constraints as adaptive challenges. New York, NY: Cambridge University Press.

Heckhausen, J. (2000). Evolutionary perspectives on human motivation. American Behavioral Scientist, 43, 1015-1029. doi:10.1177/ 00027640021955739

Heckhausen, J., \& Brim, O. G. (1997). Perceived problems for self and others: Self-protection by social downgrading throughout adulthood. Psychology and Aging, 12, 610-619. doi:10.1037/0882-7974.12.4.610

Heckhausen, J., Dixon, R. A., \& Baltes, P. B. (1989). Gains and losses in development throughout adulthood as perceived by different adult age groups. Developmental Psychology, 25, 109-121. doi:10.1037/00121649.25.1.109

Heckhausen, J., \& Schulz, R. (1995). A life-span theory of control. Psychological Review, 102, 284-304. doi:10.1037/0033-295X.102.2.284

Heckhausen, J., \& Schulz, R. (1998). Developmental regulation in adulthood: Selection and compensation via primary and secondary control. In J. Heckhausen \& C. S. Dweck (Eds.), Motivation and self-regulation across the life span (pp. 50-77). New York, NY: Cambridge University Press. doi:10.1017/CBO9780511527869.004

Heckhausen, J., \& Schulz, R. (1999). The primacy of primary control is a human universal: A reply to Gould's (1999) critique of the life-span theory of control. Psychological Review, 106, 605-609. doi:10.1037/ 0033-295X.106.3.605

Heckhausen, J., Wrosch, C., \& Fleeson, W. (2001). Developmental regulation before and after a developmental deadline: The sample case of "biological clock" for childbearing. Psychology and Aging, 16, 400413. doi:10.1037/0882-7974.16.3.400

Heckhausen, J., Wrosch, C., \& Schulz, R. (2010). A motivational theory of life-span development. Psychological Review, 117, 32-60.

Krause, N. (1998). Stressors in highly valued roles, religious coping, and mortality. Psychology and Aging, 13(2), 242-255. doi:10.1037/08827974.13.2.242

Lachman, M. E., \& Weaver, S. L. (1998). Sociodemographic variations in the sense of control by domain: Findings from the MacArthur studies of midlife. Psychology and Aging, 13(4), 553-562. doi:10.1037/08827974.13.4.553

Lang, F. R., \& Heckhausen, J. (2001). Perceived control over development and subjective well-being: Differential benefits across adulthood. Journal of Personality and Social Psychology, 81, 509-523. doi:10.1037/ 0022-3514.81.3.509

Maxwell, S. E. (2000). Sample size and multiple regression analysis. Psychological Methods, 5(4), 434-458. doi:10.1037/1082-989X.5.4.434

Mossey, J. M., Havens, B., Roos, N. P., \& Shapiro, E. (1981). The Manitoba Longitudinal Study on Aging: Description and methods. The Gerontologist, 21, 551-559. doi:10.1093/geront/21.5.551

Neugarten, B. L., Havighurst, R. J., \& Tobin, S. S. (1961). The measurement of life satisfaction. Journal of Gerontology, 16, 134-143.

Parker, M. G., Thorslund, M., \& Nordstrom, M. L. (1992). Predictors of mortality for the oldest-old: A 4-year follow-up of community-based elderly in Sweden. Archives of Gerontology and Geriatrics, 14, 227237. doi:10.1016/0167-4943(92)90023-W

Peng, Y. (1993). Primary and secondary control in American and ChineseAmerican adults: Cross-cultural and life-span developmental perspectives (Unpublished doctoral dissertation). Brandeis University, Waltham, MA.

Rakowski, W., \& Cryan, C. D. (1990). Associations among health perceptions and health status within three age groups. Journal of Aging and Health, 2, 58-80. doi:10.1177/089826439000200105

Rosenberg, S. J., Hayes, H. R., \& Peterson, R. A. (1987). Revising the Seriousness of Illness Rating Scale: Modernization and re-standardization. International Journal Psychiatry in Medicine, 17(1), 85-92.

Sarkisian, C. A., Prohaska, T. R., Davis, C., \& Weiner, B. (2007). Pilot test of an attributional retraining intervention to raise walking levels in sedentary older adults. Journal of the American Geriatrics Society, 55, 1842-1846. doi:10.1111/j.1532-5415.2007.01427.x

Schulz, R., \& Heckhausen, J. (1996). A life span model of successful aging. American Psychologist, 51, 702-714. doi:10.1037/0003066X.51.7.702

Schulz, R., Heckhausen, J., \& Locher, J. L. (1991). Adult development, control, and adaptive functioning. Journal of Social Issues, 47(4), 177-196.

Stevens, J. P. (2002). Applied multivariate statistics for the social sciences (4th ed.). Mahwah, NJ.: Erlbaum.

Stones, M. J., Kozma, A., Hirdes, J., Gold, D., Arbuckle, T., \& Kolopack, P. (1996). Short Happiness and Affect Research Protocol (SHARP). Social Indicators Research, 37(1), 75-91. doi:10.1007/BF00300270 
Tabachnick, B. G., \& Fidell, L. S. (2001). Using multivariate statistics (4th ed.). Boston, MA: Allyn \& Bacon.

Thompson, S. C., Nanni, C., \& Levine, A. (1994). Primary versus secondary and central versus consequence-related control in HIV-positive men. Journal of Personality and Social Psychology, 67, 540-547. doi: 10.1037/0022-3514.67.3.540

Thomsen, A. H., Compas, B. E., Colletti, R. B., Stanger, C., Boyer, M. C., \& Konik, B. S. (2002). Parent reports of coping and stress responses in children with recurrent abdominal pain. Journal of Pediatric Psychology, 27, 215-226. doi:10.1093/jpepsy/27.3.215

Wahl, H.-W., Becker, S., Burmedi, D., \& Schilling, O. (2004). The role of primary and secondary control in adaptation to age-related vision loss: A study of older adults with macular degeneration. Psychology and Aging, 19(1), 235-239. doi:10.1037/0882-7974.19.1.235

Weinberg, L. E. (2001). The effects of attributional retraining, age, and perceived control on health-related cognitions: A longitudinal field study of older adults attending geriatric day hospitals (Unpublished doctoral dissertation). University of Manitoba, Winnipeg, Canada.

Weisz, J. R., McCabe, M. A., \& Dennig, M. D. (1994). Primary and secondary control among children undergoing medical procedures: Adjustment as a function of coping style. Journal of Consulting and Clinical Psychology, 62, 324-332. doi:10.1037/0022-006X.62.2.324

Weisz, J. R., Thurber, C. A., Sweeney, L., Proffitt, V. D., \& LeGagnoux, G. L. (1997). Brief treatment of mild-to-moderate child depression using primary and secondary control enhancement training. Journal of Consulting and Clinical Psychology, 65, 703-707. doi:10.1037/0022-006X.65.4.703
White, R. W. (1959). Motivation reconsidered: The concept of competence. Psychological Review, 66, 297-333. doi:10.1037/h0040934

Wolinsky, F. D., Arnold, C. L., \& Nallapati, I. V. (1988). Explaining the declining rate of physician utilization among the oldest-old. Medical Care, 26(6), 544-553. doi:10.1097/00005650-198806000-00003

Wrosch, C., Heckhausen, J., \& Lachman, M. E. (2000). Primary and secondary control strategies for managing health and financial stress across adulthood. Psychology and Aging, 15, 387-399. doi:10.1037/ 0882-7974.15.3.387

Wrosch, C., Scheier, M. F., Miller, G. E., Schulz, R., \& Carver, C. S. (2003). Adaptive self-regulation of unattainable goals: Goal disengagement, goal reengagement, and subjective well-being. Personality and Social Psychology Bulletin, 29(12), 1494-1508. doi:10.1177/0146167203256921

Wrosch, C., \& Schulz, R. (2008). Health-engagement control strategies and 2-year changes in older adults' physical health. Psychological Science, 19, 537-541. doi:10.1111/j.1467-9280.2008.02120.x

Wrosch, C., Schulz, R., \& Heckhausen, J. (2002). Health stresses and depressive symptomatology in the elderly: The importance of health engagement control strategies. Health Psychology, 21, 340-348. doi: 10.1037/0278-6133.21.4.340

Wyler, A. R., Masuda, M., \& Holmes, T. H. (1968). Seriousness of Illness Rating Scale. Journal of Psychosomatic Research, 11, 363-374. doi: 10.1016/0022-3999(68)90033-0

Zarit, S. H., Johansson, B., \& Malmberg, B. (1995). Changes in functional competency of the oldest old: A longitudinal study. Journal of Aging and Health, 7, 3-23. doi:10.1177/089826439500700101

\section{Appendix}

\section{Three-Step Strategy Assessment}

\section{Step 1: Identification of Health-Related Restrictions}

How often, if ever ( 0 = never, $1=$ sometimes, $2=$ often $)$, has your [insert health condition] interfered or restricted you in terms of ...

\section{Achievement tasks}

... completing important projects related to your work or volunteer activities.

... completing important nonroutine projects (e.g., building fences, making curtains, canning).

... performing day-to-day tasks in the house (e.g., preparing meals, housework).

... performing tasks around the yard (e.g., lawn care, routine outdoor maintenance).

... performing tasks away from the home (e.g., shopping, banking).

\section{Leisure activities}

... leisure activities (e.g., golf, reading, walking, etc.).

\section{Affiliative activities}

... social activities (e.g., visiting friends/family).

... spiritual activities (e.g., going to meetings/church).

\section{Step 2: Identification of Most Restricted Domain}

You mentioned that your [insert health condition] has restricted you in several ways. In which of these ways have you been restricted most often?

\section{Step 3: Assessment of Strategy Use}

When you have difficulty with [insert task/activity], how often ( 0 = never, 4 = almost always) do you ...

\section{Engagement (persistence, task modification)}

... continue doing them just as you always have?

... exert more effort in order to do them?

... try to do only some parts of them that you can still do?

... allow yourself more time to complete them?

... continue to try to do these tasks, but do them less often

Disengagement (downgrading perceived importance)

... see these tasks as being less important than you once did?

... tell yourself that it is just not necessary to do these?

Self-protection (positive reappraisal, social comparison)

... look for a positive side to your struggle?

... tell yourself that others your age have worse problems?

Note. Italics denote exact wording. When appropriate, the word tasks was replaced with activities.

Received January 9, 2009 Revision received February 11, 2010 Accepted February 18, 2010 